\title{
Kestemont, Handbook on Legal Methodology. A Review
}

\author{
(Book review of Kestemont, L. (2018). Handbook \\ on Legal Methodology. From Objective to Method. \\ Cambridge: Intersentia, xiii + 97 pp.)
}

Wibren van der Burg*

Searching for material in courses on research methods can be challenging. There are many texts on comparative law, and there are some useful texts on interdisciplinary legal research -mostly on socio-legal studies. However, as far as traditional legal doctrinal research is concerned, there is a serious problem. Many textbooks are available on legal research methods in English, but most of them focus on practical skills in legal practice rather than on academic research. ${ }^{1}$ Moreover, most of them are strongly embedded in the Common Law tradition, which makes them less useful for scholars and students with a Civil Law background.

This book is therefore really welcome in that it partly fills the gap. Kestemont's concise, well-written and accessible guide will be very helpful to Master's and Ph.D. students embarking on doctrinal research projects. Of special note is her repeated emphasis on the importance of being explicit about methods and about the choices made in every step of the analysis. Even though it has major limitations, to be discussed in the next section, in my view it is currently the best available text in English.

The main part of the book is its distinction of seven research objectives for traditional legal research. For each of these objectives Kestemont discusses possible methods to realize them, and reflects extensively on methodological difficulties and risks associated with each method. The first of the seven objectives distinguished is description: describing and systematically analysing 'legal constructs in all their components in order to present them in an accurate, significant and orderly manner.' (In the UK, this is often called expository research.) Other objectives are classification, comparison, theory building (which includes constructing a legal doctrine), explanation, evaluation and recommendation. The typology seems defensible, although I would have structured some of the objectives differently. For example, systematically describing and analysing the legal sources (labelled as description) and constructing a legal doctrine (labelled as theory

\footnotetext{
* Wibren van der Burg, Erasmus School of Law, Erasmus University of Rotterdam and School of Law, Queen Mary University of London.

1 An exception is Salter \& Mason (2007).
} 
building) are so strongly intertwined that it seems artificial and confusing to distinguish them. Moreover, in my view, analysis of the normative principles and values underlying a legal order should have been presented as a separate objective instead of being included under explanation, because this often requires a more normative analysis than the word explanation suggests. Even so, such typologies will always be partly controversial. ${ }^{2}$

The central idea is that the choice of research objectives has major implications for the methods to be employed. The core of the book is an extensive discussion of these methods ( 1 chapter of 56 pages - more than half the book). Kestemont not only discusses which methods belong to which objective, but also cautions researchers about the possible risks and difficulties that they may encounter. She does not add many new insights but builds on the existing literature (especially the recent Dutch literature) and combines insights from various sources to construct a coherent and systematic presentation. Kestemont is the first to collect these scattered insights and present them accessibly to students and scholars.

\section{Criticisms}

Despite its merits there are major limitations. First, Kestemont calls it a handbook, a title that does not suit the book. To me a less pretentious title such as 'Ph.D. student guide' would be more apt not only because it comprises only 100 pages, but mainly because it does not cover many themes that I would expect in a handbook on legal methodology, such as issues of research design, formulation of research questions and subquestions, embedding research questions in the state of the art, and constructing and executing a plan. ${ }^{3}$ Moreover, although its focus on doctrinal research can be perfectly justified, at too many places it fails to signal that a restriction to doctrinal research may simply not be feasible for certain objectives or, at least, leads to very limited and one-sided outcomes. Providing recommendations for legal reform without any empirical and normative insights leads to very shallow and biased results. Doctrinal construction without philosophical analysis of the fundamental concepts and principles of the legal order is often incomplete. Of course, it is defensible to restrict oneself to doctrinal research, but a handbook should have to signal that this choice may have major consequences. I do not suggest that all research needs to be interdisciplinary - certainly not - but in my view researchers should be made aware that choosing to include only doctrinal research would have an impact on the completeness, soundness and plausibility of their analysis and conclusions.

2 For example, Curry-Sumner et al. (2010) present a different typology of types of questions. Part of the differences may stem from their inclusion of non-doctrinal research questions.

3 Another legal research textbook has also been published in 2018, but in Dutch: Van Dijck, Snel \& Van Golen (2018). It discusses many important themes missing in Kestemont's book, such as formulating research questions, doing literature research and presentation of the results. However, its discussion of research objectives and methods is much shorter than Kestemont's. 
These restrictions can partly be remedied by teachers. In my classes in research methods in Rotterdam and Zagreb, I combined this book with additional texts. Curry-Sumner et al. (2010) provides - very elementary - insights into matters of research design; Van Klink \& Taekema (2011) can be used to add interdisciplinary perspectives as well as discussions on the specific characteristics of doctrinal research. Such supplementary readings can and should be used in classes. Even so, I believe this book would have been better if it had more explicitly indicated what is missing and how it could be supplemented by additional texts. This oversight may have resulted from making research objectives rather than research questions central. If you focus on research questions, you more easily understand that you may need interdisciplinary research to answer them fully - or that you need to rephrase them so that your research project becomes feasible.

A second criticism is that Kestemont does not practice what she preaches. She does rightly emphasise the importance of paying attention to dissent. Researchers should avoid confirmation bias and explicitly search for views that contradict their own and discuss those. However, there is hardly any critical discussion in her book of views that do not fit her own approach. An intensive debate in the past two decades has centred on legal research methods, especially in the Netherlands. Her book is to be recommended for using much of those materials and presenting their results to a broader audience. She deserves credit for eclectically picking ideas from various authors to construct some middle-of-the-road positivist methodology. Yet the implicit message is that a broad consensus prevails on research methods. No critical footnote at all is to be found referring to authors she does not agree with, let alone a critical discussion of why they are wrong. A book like this should have contained ample references to dissenting authors, critical perspectives, and so on. There are none whatsoever. For example, no reference has been made to critical voices on comparative law like Legrand, or to authors who have suggested that doctrinal research should be held up to methodological standards of empirical disciplines (like Epstein \& King), or to authors arguing that doctrinal construction cannot rely on social sources alone but needs inevitably to rely on arguments of a political or moral nature (like Dworkin). Nor are there any critical perspectives arguing that doctrinal research should include laying bare ideological assumptions and biases of legal orders, such as Critical Legal Studies or critical feminist, queer and race studies. I am not suggesting that a book like this should have discussed them all in extenso - it cannot be an encyclopaedia - but students should at least be made aware of those dissenting voices and critical perspectives and offered some suggestions on how to pursue them if they seem appealing and relevant to their research.

Third, the book has a strong positivist bias, both in the sense of legal positivism as a view of how to understand law and in the sense of scientific positivism. The descriptive objective is presented as the aim to describe and systematise positive law on the basis of social sources only. Kestemont extensively discusses methods of interpretation for various legal sources, which may be very helpful for law students with a scant background in jurisprudence. However, she does not even mention the possibility that in constructing legal doctrine we may also need to rely on natural law or moral-legal principles, as natural lawyers and Dworkinians, 
respectively, would suggest. I personally believe that it is simply impossible to do good doctrinal research without also relying on arguments that refer to the general values and principles behind the legal order and thus to arguments that need to go beyond the traditional legal sources. Again, Kestemont's implicit positivist position is defensible, but in a scholarly handbook, aiming to show students the state of the art with regard to methodology, it should at least be mentioned that there are other views on what doctrinal research requires, and she should have argued why she does not hold that view.

There is also a positivist bias with regard to methodology. The book lays out what needs to be done: the various steps to be taken and the points in the argument at which explicit choices are necessary. But it says little about how and why to do it. What arguments would lead to a preference for one method of interpretation over the other if the outcomes are in conflict? What arguments would assign more weight to one value above the other if they led to different evaluations? How should we balance, how should we collect and select materials, how do we justify our choices at every step in our analysis? Kestemont remains largely silent about it. Frequently, she refers to statements such as those that suggest that it depends on the frame of reflection of the researcher (without discussing how to develop, criticise or revise our frames) or that it is up to the researcher. I believe that we should do more than this and that we can do more than this. We may expect researchers to justify their methodological and normative choices with good arguments. Normative judgments have a subjective dimension, but that does not imply that they are purely arbitrary subjective choices. Kestemont treats legal research consistently as if it is a purely descriptive practice. In my view, it is, first and foremost, an argumentative practice. Lawyers present arguments to justify their interpretations and normative positions in order to convince courts and legislatures. Similarly, legal scholars should provide arguments to justify their interpretations of the current law and their normative positions. Arguments can be stronger and weaker, and the academic forum should be able to assess them even if the assessments cannot always be fully conclusive. It is disappointing that Kestemont does not discuss these issues at all.

This leads me to my final critique, which must be preceded by a laudatory comment. This book is the first legal methodology book that extensively pays attention to objectives of evaluation and recommendation. Having broadly searched the literature on this theme, I have noted that most texts either simply ignore it or include only a few general paragraphs. ${ }^{4}$ Kestemont devotes twelve pages to it. Even so, she shows us a number of questions to be addressed, but not how to answer them. Evaluations and recommendations strongly depend on a frame of reference, according to Kestemont, but how precisely can such a frame be critically assessed and adapted? She argues that we must pay attention to interpretations of our normative criteria and then to operationalisations. But how do we decide which interpretations and operationalisation of, for example, the non-discrimination principle we should choose or construct? There is nothing here that 
can guide students or scholars in making their choices and justifying these to the academic forum (or to their supervisors).

I have been very critical about some aspects of the book, especially about what is missing and about implicit biases. But to return to my main evaluation, this book will be very useful in research methods classes. Obviously, it needs to be supplemented by other available readings, and also by materials yet to be written. I do hope that in the future someone will embark on a broader handbook on legal methodology. For now, however, it would be well to consider it obligatory reading for anyone who wants to do legal doctrinal research.

\section{References}

Curry-Sumner, I., Kristen, F., Van der Linden-Smith, T. \& Tichelaar, J. (2010). Research Skills. Instruction for Lawyers, Nijmegen: Ars Aequi Libri.

Salter, M. \& Mason, J. (2007). Writing Law Dissertations. An Introduction and Guide to the Conduct of Legal Research, Harlow: Pearson Education Limited.

Van der Burg, W. (2019, forthcoming). 'The Merits of Law: An Argumentative Framework for Evaluative Judgements and Normative Recommendations in Legal Research'. Archiv für Rechts- und Sozialphilosophie.

Van Dijck, G., Snel, M. \& Van Golen, T. (2018). Methoden van rechtswetenschappelijk onderzoek. Den Haag: Boom juridisch.

Van Klink, B. \& Taekema, H.S. (Eds.). (2011). Law and Method. Tübingen: Mohr Siebeck. 